\title{
Benefits of Kinesiology Tape on Tendinopathies: A Systematic Review
}

\author{
Miguel Ortega-Castillo', Lidia Martin-Soto', Ivan Medina-Porqueres ${ }^{1}$ \\ Affiliations: 'University of Malaga, Department of Physical Therapy, Faculty of Health Sciences, Malaga, Spain
}

Correspondence: I. Medina-Porqueres, University of Malaga, Faculty of Health Sciences, Department of Physical Therapy, Arquitecto Francisco Peñalosa St, 29010 Malaga, Spain. E-mail: imp@uma.es

ABSTRACT The purpose of this systematic review was to produce a best evidence synthesis of the effects of Kinesiology Tape (KT) in the treatment of tendinopathies. An electronic search on five databases (PubMed, Cumulative Index to Nursing and Allied Health Literature (CINAHL), Cochrane Library, SportDiscus, and Physiotherapy Evidence Database (PEDro)) was conducted. Studies were included if (1) patients suffered from tendinopathy; (2) isolated KT was applied in at least one group; (3) comparisons between other techniques were developed; (4) outcomes based on pain, function, disability, or quality of life were analysed. Two reviewers independently extracted data and assessed methodological quality using the Physiotherapy Evidence Database (PEDro) scale. A total of 13 articles met the eligibility criteria, involving 454 participants. Nine of these studies presented upper extremity tendinopathies, and four explored lower extremity tendinopathies. Selected papers ranged from low to high quality, with an average score of 5 on the PEDro scale. According to our findings, there is limited evidence to support KT alone for the treatment of tendinopathies beyond the short-term. Due to the mixed methodological quality and the insufficient number of clinical trials, larger, long-term, high-quality studies are needed to support the theory that tendinopathies can benefit from KT applications.

KEY WORDS kinesiotape, bandaging, tendon disorder, kinesiotaping

$@ M J S S M o n t e n e g r o$

KINESIOTAPE ON TENDINOPATHIES: A REVIEW

http://mjssm.me/?sekcija=article\&artid=205

\section{Introduction}

Tendon disorders are both acute, with partial or complete rupture components (Docheva et al., 2015), and chronic, with a duration of symptoms of greater than months being the most common presentations (Kaux et al., 2011). Nearly $30 \%$ of general practice consultations related to musculoskeletal pain involve tendon impairments (Kaux et al., 2011), reaching similar prevalence to those injuries related to sports activity (Khan \& Scott, 2009). However, and although the overuse factor is widely accepted to be significant, the role of inflammation in the different phases of tendinopathy is not completely understood (Rees et al., 2014). In terms of tendon management, a conservative approach shows positive effects in improving pain and function in some studies (Fournier \& Rappoport, 2005; Rees et al., 2006), but the ideal treatment for tendon injuries represent a challenge and remains unclear (Skjong et al., 2012).

Kinesiotape (KT) is a therapeutic taping technique developed by Dr Kenzo Kase in Japan in the mid-1970s (Halseth et al., 2004). Research has shown that a wide variety of musculoskeletal conditions such as patellofemoral pain (Campbell \& Valier, 2016; Chang et al., 2015; Kurt et al., 2016), carpal tunnel syndrome (Aktürk et al., 2018) and shoulder impingement syndrome (Hsu et al., 2009; Shih et al., 2018) may benefit from this technique. This is not only in the context of musculoskeletal disorders, as the number of clinical conditions in which KT is gaining importance is increasing, including ophthalmological (Costin, 2018), urological (Krajczy et al., 2018), vascular (Aguilar-Ferrándiz et al., 2014) and neurological conditions (Jaraczewska \& Long, 2006; Kalichman et al., 2010; Unger et al., 2018). Among its actions are pain relief (Ay et al., 2017; Hazar Kanik et al., 2018; Lim et al., 2013), ROM improvement (Yoshida \& Kahanov, 2007), injury prevention (Berezutsky, 2018; Hsiao-Yun Chang et al., 2018; Williams et al., 2012), muscle activity facilitation (Wong et 
al., 2012; Yeung et al., 2015) or inhibition (Abubaker \& Muaidi, 2018; Davison et al., 2016), lymphatic drainage (Taradaj et al., 2014; Tsai et al., 2009), joint position sense improvement (Kurt et al., 2016), improved proprioception and kinaesthetic awareness (Bischoff et al., 2018; Hosp et al., 2015; Seo et al., 2016), and dynamic balance enhancement (Hsiao-Yun Chang et al., 2018). Typical KT micro-convolutions, which provoke a lifting of the skin over the underlying tissue, may constitute a physical-base explanation. A psychological component has also been considered with regards to the support, comfort, and security perceived by patients (Vercelli et al., 2013).

The purpose of this study was to synthesize the available evidence regarding the benefits and harms of isolated KT for the treatment of tendinopathies. Recent systematic reviews have indicated a lack of consistent evidence regarding the efficacy of KT on musculoskeletal disorders (Mostafavifar et al., 2012; Parreira et al., 2014). Understanding the effect of KT on tendinopathy may change the therapeutic approach itself. Current therapeutic tendencies for tendinopathies widely vary, ranging from eccentric exercise and manual therapy to more invasive approaches such as dry needling (Aicale et al., 2018), with most treatments essentially focusing their action on increasing blood flow to the tendon. It has been postulated that the KT lifting effect may improve blood and lymphatic flow and reduce pain by mechanically decreasing pressure on pain receptors (Lee \& Yoo, 2012). Therefore, the primary goal of this review was to ascertain the impact of kinesiology tape in the affected tendon in every different way this structure elicits a deficit.

Furthermore, despite the existence of systematic reviews that assess the effect of various interventions for both generic (Andia et al., 2014; de Vos et al., 2010; Gambito et al., 2010; Lui \& Ng, 2013; Sanderson \& Bryant, 2015) and concrete, well-defined (Habets \& van Cingel, 2015; Kearney \& Costa, 2010; Larsson et al., 2012; Littlewood et al., 2012; Wilson et al., 2018) tendinopathies, some of them firstly regarding the effectiveness of isolated KT for treating distinct musculoskeletal conditions and tissues, specifically ankle (Wang et al., 2018; Wilson \& Bialocerkowski, 2015) and lower back disorders (Li et al., 2018; Nelson, 2016), no previous reviews have been identified that define specifically tendinopathies as a focus for evaluation. Considering this gap in the literature, there is justification to undertake a review to assess the effectiveness of isolated KT in the management of tendinopathies.

\section{Methods}

\section{Study protocol and registration}

This systematic review was conducted and reported according to Preferred Reporting Items for Systematic reviews and Meta-Analyses (PRISMA) recommendations (Liberati et al., 2009). The study was registered with the International Prospective Register of Systematic Reviews (PROSPERO). It was registered after a pilot search and prior to updated data search and extraction (Registration number CRD42014013832). No funding was received in the preparation of this study.

\section{Data Sources and Search Strategy}

Individualized, computer-based search strategies for PubMed, Cumulative Index to Nursing and Allied Health Literature (CINAHL), Cochrane Library, SportDiscus, and Physiotherapy Evidence Database (PEDro) were conducted in January 2018, with no restriction on the earliest date. The search strategy was based on the medical subject heading (MeSH) and non-MeSH search terms. The following keywords were used: Kinesiotap $^{*}$, Kinesio Tap ${ }^{*}$, Kinesio, Kinesio-tap ${ }^{*}$, Neuromuscular Tape, and Tendinopathy. The various synonyms of KT were also combined with the terms Tendon, Tendon Injuries, Tendinitis, Tendinosis, and the following specific tendinopathies Achilles tendinopathy, Jumper's knee, Patellar tendinopathy, Epicondylitis, Medial elbow epicondylar tendinopathy, Medial epicondylitis, Rotator cuff tendinitis, Subacromial impingement syndrome, De Quervain's syndrome, and De Quervain disease. The electronic search was complemented by hand searching reference lists from previous systematic reviews and related papers. In addition, a recognized expert in this field was consulted in an attempt to identify any further published studies.

\section{Eligibility Criteria for Selection}

A PICO (population or problem, intervention, comparison, outcomes) question was established as a framework and followed during the literature selection process (Table 1). According to this, studies were included if they met the following criteria: (i) population: patients with tendinopathy; (ii) intervention: KT was applied as a treatment method comprising at least one arm in the study; (iii) comparison: between KT and placebo, control, other tapes or techniques; (iv) outcomes: all clinical outcomes were analysed, including those based on pain, function, disability, or quality of life. Exclusion criteria were reviews, meta-analyses, case reports, expert opinions, and studies using multimodal approaches or mixed/hybrid bandage techniques. Articles, editorials, and letters published in abstract form were also discarded. Studies in languages other than English were not considered during the entire search. No date restrictions were used in order to maximize information collection.

To select relevant articles, titles and abstracts of all identified citations were independently screened by two reviewers (LM-S, IM-P) applying the a priori inclusion/exclusion criteria. Agreement between the two authors regarding which articles to read in full was determined by consensus. Full-text articles were retrieved if the abstract provided insufficient information to establish eligibility or if the article had passed the first eligibility screening. The reference lists of all selected publications were screened by all reviewers to retrieve relevant publications that were not identified in the computerized search. A predesigned data extraction form was used to collect and synthesize the data. The study characteristics extracted were study design, target 


\begin{tabular}{|c|c|c|c|}
\hline & Definition & Search Key Words & Studies \\
\hline Population (P) & Any participants & Not set & $\begin{array}{l}\text { Studies that evaluated the effect of kinesiotape on clinical } \\
\text { and functional parameters in adults of any age with } \\
\text { tendinopathy, regardless of gender, clinical stage and type } \\
\text { of tendinopathy. }\end{array}$ \\
\hline Intervention (I) & Any form of kinesiotape in isolation & Kinesio* OR kinesiotap* & $\begin{array}{l}\text { Studies that reported the effect of kinesiotape on clinical } \\
\text { and functional parameters in adults with tendinopathy. } \\
\text { The intervention could take place in any setting and be } \\
\text { delivered to a group or individual participant. All types of } \\
\text { kinesiotape application were considered for inclusion. }\end{array}$ \\
\hline Comparison (C) & Any interventions & Not set & $\begin{array}{l}\text { The studies that compared kinesiotape with any other } \\
\text { intervention. }\end{array}$ \\
\hline Outcome (O) & $\begin{array}{l}\text { Tendinopathy } \\
\text { Tendon disorder } \\
\text { Tendonitis } \\
\text { Tendinosis }\end{array}$ & (pain) OR (functional outcome) & $\begin{array}{l}\text { Clinical and functional parameters accompanying } \\
\text { tendinopathy measured by specific or patient-reported } \\
\text { assessment tools. }\end{array}$ \\
\hline Study Design (S) & $\begin{array}{l}\text { Randomized and non-randomized } \\
\text { clinical studies }\end{array}$ & Not set & Both randomized and non-randomized clinical studies \\
\hline
\end{tabular}

population (gender, age), sample size, type of injury, follow-up duration, interventions (detailed information about the application of KT), and all reported outcomes. Data were extracted independently by two authors (LM-S and MO-C) and confirmed by one other author (IM-P). Any discrepancies were settled by further discussion and consensus. Papers not meeting inclusion criteria and duplicates were excluded. All decisions were discussed and agreed upon by three researchers, ensuring a rigorous application of the inclusion criteria.

\section{Methodological Quality Assessment}

The risk of bias was assessed using the critical evaluation of the Physiotherapy Evidence Database (PEDro) scale (Maher et al., 2003). This tool provides credibility or internal validity evaluation, as well as determining whether the trial contains sufficient statistical information to make it interpretable. Individual reviews were discussed among researchers resolving the points of disagreement by group consensus. Studies with a PEDro score $\geq 5$ were considered at low risk of bias and high methodological quality (Moseley et al., 2002). According to Foley et al., studies with a PEDro score of $\geq 6$ represent level 1 evidence $(6-8=$ good; $9-10=$ excellent $)$ whereas studies scoring $\leq 5$ reach level 2 evidence $(4-5=$ acceptable; $<4=$ poor) (Foley et al., 2003).

\section{Outcomes of interest}

Pain reduction over time and measures of functional recovery were our primary outcomes of interest. Pain was measured via a visual analogue scale (VAS) in six of the 13 studies (Dilek et al., 2016; Firth et al., 2010; Göksu et al., 2016; Homayouni et al., 2013b; Homayouni et al., 2016; Thelen et al., 2008), while two of the 13 studies used the Numerical Pain Raring Scale (NPRS) (Au et al., 2017; Massei et al., 2017). Types of painful sensation assessed included load-induced pain, pressure pain threshold, tenderness, pain at rest/activity, pain at daily living activities, pain at night, and palpation-induced pain. Strength data were also obtained through maximal grip strength, maximal wrist flexor strength, pain-free grip strength, force sense, rate of loading and power (using single-hop test and counter-movement jump (CMJ) procedures) (Au et al., 2017; Chang et al., 2012; Chang et al., 2013; Dilek et al., 2016; Firth et al., 2010; Griebert et al., 2016; Massei et al., 2017). Functional improvement was addressed according to different parameters depending on the specific impairment, such as muscle activity (motion tracking, EMG activity) muscle excitability (Hoffman reflex test), ROM and pain-free ROM, along with validated patient-reported outcome reports (PROs), such as the Shoulder Pain And Disability Index (SPADI), Victorian Institute of Sports Assessment - Achilles (VISA-A), Patient Rated (Forearm) Tennis Elbow Evaluation Questionnaire (PRTEE), Nirschl score, and Star Excursion Balance Test (SEBT) (Au et al., 2017; Dilek et al., 2016; Firth et al., 2010; Göksu et al., 2016; Liu et al., 2007; Massei et al., 2017; Shakeri et al., 2013; Thelen et al., 2008).

\section{Results}

Study Identification

A database search was performed using MEDLINE, SPORT Discus, CINAHL, PEDro, and the Cochrane Library, yielding 34 citations specific to the search terms used. Among them, 26 were from Pubmed, three from CINHAL, and three from SportDiscus. Two additional studies that met the criteria for inclusion were identified by hand search and checking the reference lists of selected studies. Removal of duplicates resulted in 21 references, whereas three were excluded by language, two after discovering patients did not suffer from tendinopathy, and nine after verifying that multimodal approaches were developed. Following consensus, a review of titles and abstracts resulted in the exclusion of seven references as they did not meet the eligibility criteria. After screening the citations by title and abstract, 13 studies that used isolated KT to treat tendinopathy were finally selected in the qualitative synthesis. Figure 1 represents the PRISMA flowchart for the selection process. 

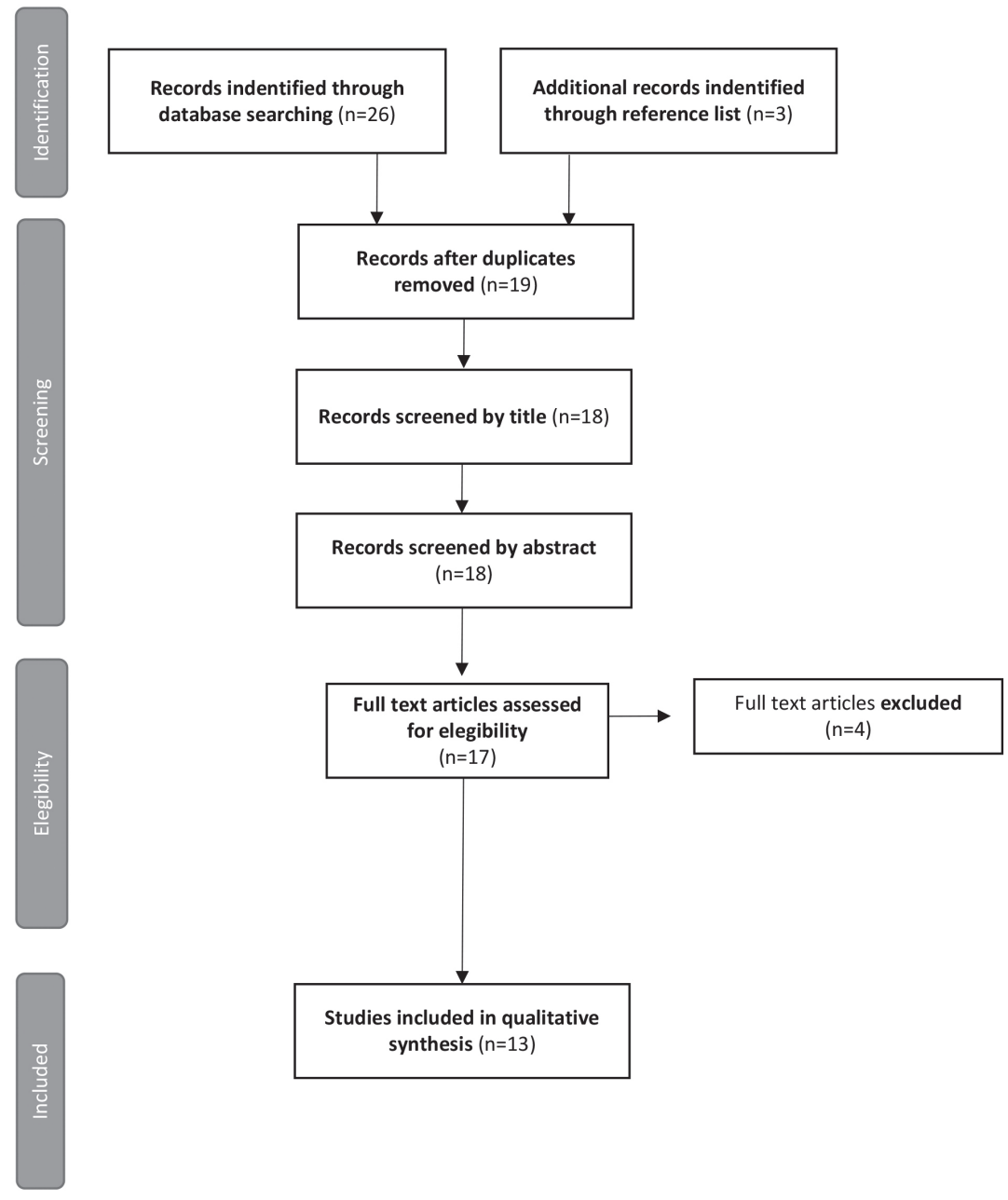

FIGURE 1. PRISMA flow diagram of search results

\section{Study Characteristics}

A total of 13 studies finally comprised this review, involving 454 participants ( $n=193$ comparisons, $n=261$ interventions). Eight of them were conducted in Asia, whereas three studies were originally from North America and three from Europe. The final selection was published from 2007 to 2017. The included studies involved both athletes $(n=64)$ and non-athletes $(n=390)$. A summary of the included studies is presented in Table 2.

\begin{tabular}{|c|c|c|c|c|c|c|}
\hline Authors, Year & $\begin{array}{l}\text { Type of } \\
\text { study }\end{array}$ & $\begin{array}{l}\text { Sample } \\
\text { size }\end{array}$ & $\begin{array}{l}\text { Intervention } \\
\text { groups }\end{array}$ & Type of injury & Intervention/Measures & Outcomes \\
\hline $\begin{array}{l}\text { Chang et al., } \\
201371\end{array}$ & RCT & $\begin{array}{l}\mathrm{n}=27 \text { male } \\
\text { athletes }\end{array}$ & $\begin{array}{l}\text { Healthy athletes } \\
\text { group }(n=17) \text { and } \\
\text { affection group } \\
(n=10)\end{array}$ & $\begin{array}{l}\text { Medial elbow } \\
\text { tendinopathy }\end{array}$ & $\begin{array}{l}\text { Three taping conditions (no tape, } \\
\text { placebo tape and KT) in medial fore- } \\
\text { arm in both groups to determine its } \\
\text { clinical effectiveness in maximal } \\
\text { grip strength and force sense. }\end{array}$ & $\begin{array}{l}\text { No significant interactions in en- } \\
\text { hancing the overall strength and } \\
\text { grip strength, just in absolute force } \\
\text { sense error for KT and placebo } \\
\text { tape. }\end{array}$ \\
\hline $\begin{array}{l}\text { Firth et al., } \\
201063\end{array}$ & $\mathrm{NRCT}$ & $\begin{array}{l}\mathrm{n}=55 \text { at } \\
\text { baseline, } \\
\mathrm{n}=48 \text { at } \\
\text { the end of } \\
\text { the study }\end{array}$ & $\begin{array}{l}\text { Healthy group } \\
(n=26) \text { and } \\
\text { affection group } \\
(n=29) .7 \\
\text { subjects left the } \\
\text { study, remaining } \\
24 \text { participants } \\
\text { per group }\end{array}$ & $\begin{array}{l}\text { Achilles } \\
\text { tendinopathy }\end{array}$ & $\begin{array}{l}\text { KT on the Achilles tendon in both } \\
\text { groups to evaluate its effect on } \\
\text { single-leg jump distance, pain and } \\
\text { motor neuron excitability. }\end{array}$ & $\begin{array}{l}\text { KT had no effects on the variables } \\
\text { of the study. }\end{array}$ \\
\hline $\begin{array}{l}\text { Chang et al., } \\
201270\end{array}$ & Case control & $\mathrm{n}=27$ & $\begin{array}{l}\text { Healthy athletes } \\
\text { group }(n=17) \text { and } \\
\text { affection group } \\
(n=10)\end{array}$ & $\begin{array}{l}\text { Medial elbow } \\
\text { tendinopathy }\end{array}$ & $\begin{array}{l}\text { Three taping conditions (no tape, } \\
\text { placebo tape and KT) in both } \\
\text { groups to search for immediate ef- } \\
\text { fects in pain, strength of wrist flex- } \\
\text { ors and force sense. }\end{array}$ & $\begin{array}{l}\text { No significant changes in wrist } \\
\text { flexors strength and force sense } \\
\text { between groups. } \\
\text { Pressure pain significantly im- } \\
\text { proved in both groups for KT and } \\
\text { placebo tape. }\end{array}$ \\
\hline
\end{tabular}


(Continued from previous page)

\begin{tabular}{|c|c|c|c|c|c|c|}
\hline Authors, Year & $\begin{array}{l}\text { Type of } \\
\text { study }\end{array}$ & $\begin{array}{l}\text { Sample } \\
\text { size }\end{array}$ & $\begin{array}{l}\text { Intervention } \\
\text { groups }\end{array}$ & Type of injury & Intervention/Measures & Outcomes \\
\hline Liu et al., 200773 & Case series & $\mathrm{n}=2$ & $\begin{array}{l}\text { Affection group } \\
(\mathrm{n}=2)\end{array}$ & $\begin{array}{l}\text { Lateral } \\
\text { epicondylitis }\end{array}$ & $\begin{array}{l}\text { KT application to identify a poten- } \\
\text { tial benefit in the motion of the ex- } \\
\text { tensor carpi radialis muscles. }\end{array}$ & $\begin{array}{l}\text { Results showed a smaller extension } \\
\text { movement after } 24 \text { hours of KT. }\end{array}$ \\
\hline $\begin{array}{l}\text { Thelen et al., } \\
200862\end{array}$ & $\begin{array}{l}\text { Prospective, } \\
\text { randomized, } \\
\text { double- } \\
\text { blinded, } \\
\text { clinical trial }\end{array}$ & $n=42$ & $\begin{array}{l}\text { Control group } \\
(\mathrm{n}=21) \text { and } \\
\text { experimental } \\
\text { group }(\mathrm{n}=21)\end{array}$ & $\begin{array}{l}\text { Rotator cuff } \\
\text { tendinopathy/ } \\
\text { shoulder } \\
\text { impingement }\end{array}$ & $\begin{array}{l}\text { KT application to determine short- } \\
\text { term clinical efficacy in ROM, pain } \\
\text { and function in comparison with } \\
\text { sham taping. }\end{array}$ & $\begin{array}{l}\text { Experimental group showed im- } \\
\text { mediate significant improvements } \\
\text { just in active shoulder abduction } \\
\text { movement. } \\
\text { Pain was only significant for KT at } \\
\text { day } 1 .\end{array}$ \\
\hline $\begin{array}{l}\text { Shakeri et al., } \\
201374\end{array}$ & RCT & $n=30$ & $\begin{array}{l}\text { KT group }(n=15) \\
\text { and placebo tape } \\
\text { control group } \\
(n=15)\end{array}$ & $\begin{array}{l}\text { Subacromial } \\
\text { Impingement } \\
\text { Syndrome }\end{array}$ & $\begin{array}{l}\text { Investigate the effect of KT on pain } \\
\text { intensity during movement, noc- } \\
\text { turnal pain, and pain-free shoulder } \\
\text { ROM immediately after taping, after } \\
\text { three days and after one week, in } \\
\text { comparison with placebo taping. }\end{array}$ & $\begin{array}{l}\text { Significant changes were found } \\
\text { in the experimental group in pain } \\
\text { during movement, nocturnal pain } \\
\text { (also in control group), and pain- } \\
\text { free ROM after KT. Immediately } \\
\text { after KT, pain during movement } \\
\text { and nocturnal pain changes were } \\
\text { significantly better in the experi- } \\
\text { mental group, with no differences } \\
\text { between groups in ROM measures. } \\
\text { No significant differences between } \\
\text { groups were found after one week } \\
\text { in pain intensity and shoulder ROM. }\end{array}$ \\
\hline $\begin{array}{l}\text { Homayouni et } \\
\text { al., } 201364\end{array}$ & $\begin{array}{l}\text { Prospective } \\
\text { RCT }\end{array}$ & $n=60$ & $\begin{array}{l}\text { KT group } \\
(\mathrm{n}=30) \text { and } \\
\text { physiotherapy } \\
\text { group }(\mathrm{n}=30)\end{array}$ & $\begin{array}{l}\text { De Quervain's } \\
\text { disease }\end{array}$ & $\begin{array}{l}\text { KT application to assess changes } \\
\text { in pain and swelling in comparison } \\
\text { with physical therapy modalities } \\
\text { (paraffin, ultrasound, TENS, friction } \\
\text { massage). }\end{array}$ & $\begin{array}{l}\text { Pain significantly improved in both } \\
\text { groups, being more meaningful for } \\
\text { KT group. } \\
\text { Swelling changes were only signifi- } \\
\text { cant in KT group. }\end{array}$ \\
\hline $\begin{array}{l}\text { Dilek et al., } \\
201666\end{array}$ & Case series & $n=31$ & KT group $(n=31)$ & $\begin{array}{l}\text { Lateral } \\
\text { epicondylitis }\end{array}$ & $\begin{array}{l}\text { KT application to evaluate changes } \\
\text { in pain, grip strength, disability and } \\
\text { stage of the disease. }\end{array}$ & $\begin{array}{l}\text { Significant changes were observed } \\
\text { in all of the measured variables at } 2 \\
\text { and } 6 \text { weeks. }\end{array}$ \\
\hline $\begin{array}{l}\text { Goksu et al., } \\
201667\end{array}$ & RCT & $n=61$ & $\begin{array}{l}\text { KT group } \\
(\mathrm{n}=30) \text { and local } \\
\text { injection therapy } \\
\text { group }(\mathrm{n}=31)\end{array}$ & $\begin{array}{l}\text { Subacromial } \\
\text { Impingement } \\
\text { Syndrome }\end{array}$ & $\begin{array}{l}\text { KT application to observe potential } \\
\text { changes in pain, ROM and function, } \\
\text { in comparison with subacromial } \\
\text { corticosteroid injection therapy. }\end{array}$ & $\begin{array}{l}\text { Significant improvements were } \\
\text { found in both groups for all of the } \\
\text { measured variables, but results } \\
\text { between groups were significant } \\
\text { in favour of local injection therapy. }\end{array}$ \\
\hline $\begin{array}{l}\text { Griebert et al., } \\
201672\end{array}$ & RCT & $\mathrm{n}=40$ & $\begin{array}{l}\text { Healthy group } \\
(\mathrm{n}=20) \text { and } \\
\text { affection group } \\
(\mathrm{n}=20)\end{array}$ & $\begin{array}{l}\text { Medial } \\
\text { tibial stress } \\
\text { syndrome }\end{array}$ & $\begin{array}{l}\text { KT application in both groups to } \\
\text { study possible changes in plantar } \\
\text { pressures and rate of loading. }\end{array}$ & $\begin{array}{l}\text { Significant changes in medial mid- } \\
\text { foot time-to-peak-forces in favour } \\
\text { of healthy subjects at the begin- } \\
\text { ning, not remaining immediate } \\
\text { and } 24 \text { hours after taping, being } \\
\text { only significant in affection group. } \\
\text { Regarding lateral forefoot, signifi- } \\
\text { cant within-group differences were } \\
\text { observed between baseline and } \\
\text { immediate application, not } 24 \text { af- } \\
\text { ter taping. }\end{array}$ \\
\hline $\begin{array}{l}\text { Homayouni et } \\
\text { al., } 201665\end{array}$ & $\begin{array}{l}\text { Comparative } \\
\text { RCT }\end{array}$ & $\begin{array}{l}n=56 \text { at } \\
\text { baseline, } \\
n=46 \text { at } \\
\text { the end of } \\
\text { the study }\end{array}$ & $\begin{array}{l}\text { KT group }(\mathrm{n}=28) \\
\text { and naproxen/ } \\
\text { physical therapy } \\
\text { group }(\mathrm{n}=28) .10 \\
\text { subjects left the } \\
\text { study, remaining } \\
27 \text { and } 19 \\
\text { respectively }\end{array}$ & $\begin{array}{l}\text { Pes anserinus } \\
\text { tendino- } \\
\text { bursitis }\end{array}$ & $\begin{array}{l}\text { KT application to evaluate its ben- } \\
\text { efits in pain and swelling, in com- } \\
\text { parison with naproxen/physical } \\
\text { therapy. }\end{array}$ & $\begin{array}{l}\text { Significant changes were observed } \\
\text { in both groups, being more signifi- } \\
\text { cant for KT group. }\end{array}$ \\
\hline Au et al., 201768 & $\begin{array}{l}\text { Deceptive } \\
\text { crossover } \\
\text { trial }\end{array}$ & $\begin{array}{l}n=33 \text { at } \\
\text { baseline, } \\
n=30 \text { at } \\
\text { the end of } \\
\text { the study }\end{array}$ & $\begin{array}{l}\text { Affection group } \\
\text { ( } n=33 \text { at the } \\
\text { beginning, } n=30 \\
\text { at the end of the } \\
\text { study) }\end{array}$ & $\begin{array}{l}\text { Lateral } \\
\text { epicondylitis }\end{array}$ & $\begin{array}{l}\text { Four taping conditions (facilitatory } \\
\mathrm{KT} \text {, inhibitory } \mathrm{KT} \text {, sham } \mathrm{KT} \text { and no } \\
\text { tape) to search for immediate ef- } \\
\text { fects in grip strength, pain and EMG } \\
\text { activity }\end{array}$ & $\begin{array}{l}\text { No significant changes in any of } \\
\text { the measured variables were ob- } \\
\text { served between taping conditions. }\end{array}$ \\
\hline $\begin{array}{l}\text { Massei et al., } \\
201769\end{array}$ & Case Series & $\mathrm{n}=10$ & $\begin{array}{l}\text { Affection group } \\
(n=10)\end{array}$ & $\begin{array}{l}\text { Patellar } \\
\text { tendinopathy }\end{array}$ & $\begin{array}{l}\text { Four taping conditions (placebo } \\
\text { tape, KT, leukotape and no tape) to } \\
\text { assess immediate changes in pain, } \\
\text { ROM, strength, power and balance }\end{array}$ & $\begin{array}{l}\text { Significant changes in favour of } \mathrm{KT} \\
\text { were only observed in knee flexor } \\
\text { strength and in anteromedial and } \\
\text { posterolateral balance directions, } \\
\text { as well as for lateral directions for } \\
\mathrm{KT} \text {, leukotape and placebo tape in } \\
\text { comparison with no tape. }\end{array}$ \\
\hline
\end{tabular}

Note. RCT - Randomized Controlled Trial; NRCT - Non-randomized controlled trial; KT - Kinesiotape; ROM - Range of Motion; EMG - Electromyography. 
The selected papers ranged from low to high quality, with an average score of 5 (range 0-9) on the PEDro scale (table 3). Three studies were considered to be of high quality (PEDro score $\geq 6$ ), and ten studies were found to be of low quality (PEDro score $<6$ ). The PEDro scores for the studies in athletes and non-athletes ranged from 0 to 6 out of 10, and from 0 to 9 out of 10, respectively. In this sense, the worst-scored criterion was the blinding of the therapist, as this can not be assumed according to the intervention's nature. Concurrently, the best-scored items were between-group comparisons, randomization when allocating, and point estimates and variability. According to Foley et al. (2003), less than half $(n=5)$ of the included studies reached an acceptable level.

\section{TABLE 3. PEDro Scale scores for selected studies}

\begin{tabular}{|c|c|c|c|c|c|c|c|c|c|c|c|c|}
\hline & $\begin{array}{l}\text { PEDro } \\
\text { Final } \\
\text { score }\end{array}$ & $\begin{array}{l}\text { Eligibility } \\
\text { criteria } \\
\text { specified } \\
\text { (ítem does } \\
\text { not score) }\end{array}$ & $\begin{array}{l}\text { Random } \\
\text { allocation }\end{array}$ & $\begin{array}{l}\text { Concealed } \\
\text { allocation }\end{array}$ & $\begin{array}{c}\text { Similar } \\
\text { groups } \\
\text { at } \\
\text { baseline }\end{array}$ & $\begin{array}{c}\text { Blinding } \\
\text { of } \\
\text { subjects }\end{array}$ & $\begin{array}{c}\text { Blinding } \\
\text { of } \\
\text { therapists }\end{array}$ & $\begin{array}{c}\text { Blinding } \\
\text { of } \\
\text { assessors }\end{array}$ & $\begin{array}{c}\text { Measure } \\
\text { one key } \\
\text { outcome } \\
\text { from } 85 \% \\
\text { patients }\end{array}$ & $\begin{array}{l}\text { Intention- } \\
\text { to-treat } \\
\text { analysis }\end{array}$ & $\begin{array}{l}\text { Between- } \\
\text { group } \\
\text { statistical } \\
\text { comparisons* }\end{array}$ & $\begin{array}{c}\text { Variability } \\
\text { and point } \\
\text { measurements* }\end{array}$ \\
\hline Chang et al. & $4 / 10$ & & Yes & No & No & Yes & No & No & Yes & No & Yes & No \\
\hline Firth et al. & $4 / 10$ & & No & No & No & Yes & No & No & Yes & No & Yes & Yes \\
\hline Chang et al. & $6 / 10$ & & No & No & Yes & Yes & No & No & Yes & Yes & Yes & Yes \\
\hline Liu et al. & $0 / 10$ & & No & No & No & No & No & No & No & No & No & No \\
\hline Thelen et al. & $9 / 10$ & & Yes & Yes & Yes & Yes & Yes & No & Yes & Yes & Yes & Yes \\
\hline $\begin{array}{l}\text { Shakeri } \\
\text { et al. }\end{array}$ & $8 / 10$ & & Yes & No & Yes & Yes & Yes & No & Yes & Yes & Yes & Yes \\
\hline Au et al. & $5 / 10$ & & Yes & No & No & Yes & No & Yes & No & Yes & Yes & No \\
\hline $\begin{array}{l}\text { Griebert } \\
\text { et al. }\end{array}$ & $2 / 10$ & & No & No & Yes & No & No & No & No & No & Yes & No \\
\hline $\begin{array}{l}\text { Goksu et } \\
\text { al. }{ }^{67}\end{array}$ & $7 / 10$ & & Yes & Yes & Yes & No & Yes & No & Yes & Yes & Yes & No \\
\hline $\begin{array}{l}\text { Homayouni } \\
\text { et al. }\end{array}$ & $7 / 10$ & & Yes & Yes & Yes & No & No & No & Yes & Yes & Yes & Yes \\
\hline Dilek et al. ${ }^{66}$ & $4 / 10$ & & No & No & No & No & No & No & Yes & Yes & Yes & Yes \\
\hline $\begin{array}{l}\text { Homayouni } \\
\text { et al. }\end{array}$ & $5 / 10$ & & Yes & No & Yes & No & Yes & No & No & Yes & Yes & No \\
\hline Massei et al. & $4 / 10$ & & Yes & No & Yes & No & No & No & No & Yes & Yes & No \\
\hline
\end{tabular}

Note. ${ }^{*}$ - for at least one key outcome.

Until now, three high-quality studies showed moderate significant improvement at the final follow-up measurement when compared with conventional physical therapy (Homayouni et al., 2013b; Homayouni et al., 2016), medication (Homayouni et al., 2016), or placebo taping (Shakeri et al., 2013). An indirect ROM improvement was also found in another RCT by Thelen et al. with no further changes (Thelen et al., 2008), while Griebrt et al. (2016) uniquely demonstrated an immediate biomechanical influence which tended to disappear after 24 hours. Additionally, one low-quality study corroborates such functional and clinical amelioration in terms of associated pain and grip strength (Dilek et al., 2016). Conversely, two high-quality studies showed no beneficial effect of KT for the management of tendinopathies when compared with placebo treatment (Chang et al., 2013) or corticosteroid injection (Göksu et al., 2016). Therefore, there is weak evidence that isolated KT improves pain and/or function in tendinopathies when compared with other treatment options.

Kinesiotape on Strength and Muscle properties

Strength and muscle properties were evaluated in six studies through dynamometry, functional test, electromyography (EMG), and specific software (Au et al., 2017; Chang et al., 2012; Chang et al., 2013; Dilek et al., 2016; Griebert et al., 2016; Massei et al., 2017). Assessed outcomes included maximal grip strength, painfree grip strength, sense of related/absolute strength (both measured with a hydraulic hand dynamometer JAMAR) when assessing forearm structures, EMG activity of wrist extensors (during pain-free and maximal grip strength), rate of loading (pressure mat with a Tekscan ${ }^{\circledR}$ system), strength and power (counter-movement vertical jump procedure).

Strength in the presence of medial elbow tendinopathy was measured in two studies (Chang et al., 2012; Chang et al., 2013). Chang et al. aimed to determine the clinical effectiveness in maximal grip strength and grip force sense by the application of KT in comparison with healthy athletes (Chang et al., 2013). Three different tape dressings, including without-taping (WT), placebo KT (PKT), and KT were randomly applied with an interval of one week between measurements. In this study, significant changes among groups and taping conditions were only found in absolute force sense error $(\mathrm{p}=0.04)$, observing smaller errors for PKT and KT than WT in the experimental group $(\mathrm{p}<0.05)$. Also, WT presented larger errors than PKT in the control group. Comparing between groups, the experimental group showed smaller errors in PKT condi- 
tion $(\mathrm{p}<0.05)$. However, no significant improvements were found between groups and taping conditions for maximal grip strength and related grip force sense error ( $\mathrm{p}=0.50$ and 0.22 , respectively). In another study, Chang et al. evaluated the same muscle properties (maximal grip strength and grip force sense), applying the same three taping conditions identically, in a study comparing baseball pitchers to healthy athletes (Chang et al., 2012). Results regarding maximal wrist flexor isometric strength also showed no significant difference among the three taping modalities for both healthy groups $(\mathrm{p}=0.838)$ and the medial epicondylitis group $(\mathrm{p}=0.232)$. For absolute force sense error, significant results among three taping methods for the ME group (WT $>$ KT, p=0.023) were also found, not being significant for the healthy group. Regarding related force sense error, there was a significant difference for the healthy group $(\mathrm{p}=0.036)$ but not significant for the ME group $(\mathrm{p}=0.741)$.

Lateral epicondylitis was addressed in two studies (Au et al., 2017; Dilek et al., 2016). Au et al. (2017) aimed to evaluate pain-free grip strength, maximal grip strength (both of them measured using Jamar dynamometer) and EMG activity of wrist extensors during these two previous conditions. All participants went through four KT conditions (inhibitory KT, facilitatory KT, sham KT, and untaped), and were assessed immediately after each tape application. Results regarding pain-free and maximal grip strength showed no significant changes ( $p=0.312$ and $p=0.499$, respectively) between different conditions. Similarly, there were no significant differences in the EMG activity measures in pain-free and maximal grip strength ( $\mathrm{p}=0.618$ and $\mathrm{p}=0.774$, respectively). Dilek et al. (2016) focused on measuring grip strength using a Jamar dynamometer, and KT was applied twice a week for two weeks. Evaluations were carried out before treatment, at two weeks and six weeks after intervention. Results showed significant improvement $(\mathrm{p}<0.05)$ in handgrip scores at two and six weeks. Specifically, the handgrip strength of the affected side reached $67.5 \%$ of the unaffected side.

One study assessed KT and its effect in the presence of MTSS (Griebert et al., 2016). KT effects regarding the rate of loading and plantar pressure were evaluated in comparison with healthy subjects. A Tekscan ${ }^{\star}$ pressure mat system was used to calculate time-to-peak forces (TTPF) in each previously-divided area of the foot, including lateral forefoot (LFF), lateral midfoot (LMF), lateral rearfoot (LRF), medial forefoot (MFF), medial midfoot (MMF) and medial rearfoot (MRF). Measures were taken before (baseline), during (KT-1) and 24 hours (KT-2) after KT application. Outcomes showed significant TTPF differences at the MMF in favour of healthy participants at baseline $(\mathrm{p}=0.021)$, but not in KT-1 nor KT-2 applications, where these changes were only significant in the MTSS group ( $p=0.022$ and $p=0.043$ respectively). Moreover, the MTSS group also showed significant within-group differences between baseline and KT- 1 under the LFF ( $\mathrm{p}=0.031$ ), not remaining at KT-2 $(\mathrm{p}=0.29)$.

KT effects on patellar tendinopathy were analysed in one study by Massei et al. (Massei et al., 2017), in which four different tape conditions such as no tape (NT) as baseline session, placebo tape (PT), KT, and Leukotape (LT) were applied. Power and strength were measured using the counter-movement vertical jump procedure and electronic, hydraulic push-pull dynamometer, respectively. All subjects went through all four taping conditions, committing to four testing sessions with at least one day of rest between them. Results showed no significant changes regarding power between different taping conditions. However, significant improvements were observed in knee flexor strength when comparing KT with LT, NT and PT $(\mathrm{p}<0.05)$, but not regarding knee extensor strength, where no meaningful effect was found between taping conditions.

\section{Kinesiotape on Joint Function}

Functionality was assessed with several procedures in seven studies (Dilek et al., 2016; Firth et al., 2010; Göksu et al., 2016; Liu et al., 2007; Massei et al., 2017; Shakeri et al., 2013; Thelen et al., 2008), including the Shoulder Pain And Disability Index (SPADI), single hop test, Victorian Institute of Sports Assessment - Achilles (VISA-A), Patient Rated (Forearm) Tennis Elbow Evaluation (PRTEE), Nirschl score, and Star Excursion Balance Test (SEBT). Moreover, range of motion (ROM) variables were measured by goniometry in 4 studies(Göksu et al., 2016; Massei et al., 2017; Shakeri et al., 2013; Thelen et al., 2008), and neuron excitability was measured in one study (Firth et al., 2010). Additionally, one study comprised muscular motion tracking by ultrasonography (Liu et al., 2007).

Shoulder impingement was evaluated in three studies (Göksu et al., 2016; Shakeri et al., 2013; Thelen et al., 2008). Thelen et al. (2008) aimed to assess disability (SPADI) and pain-free ROM after KT application in comparison with sham taping. Subjects were randomly allocated in KT and sham KT groups. Measures were obtained at baseline, right after taping (except SPADI score), three and six days after the initial application, re-taping subjects on the third day after being inspected and assessed. Significant changes were found in all outcomes on the sixth-day follow-up, but none of them, apart from shoulder abduction at the first day $(\mathrm{p}=0.005)$, were more efficacious than sham taping (Thelen et al., 2008). Shakeri et al. studied the effect of KT on pain-free active shoulder ROM (abduction, flexion and scapular elevation) in comparison with placebo taping. Subjects were randomly allocated in KT and placebo KT groups, and measures were obtained at baseline, immediately after taping, three days and one week after initial application, re-taping subjects at fourth day after skin evaluation. Results showed significant improvements in all measures for both groups (except for shoulder flexion in the control group), but differences were not meaningful between them (Shakeri et al., 2013). Goksu et al. compared the effect of KT and local injection therapy. KT was applied three times at threeday intervals. Functionality was measured in terms of active flexion, abduction, internal and external rotation 
ROM goniometry and SPADI score, obtaining results at baseline, one week and four weeks after therapy. Both groups showed significant changes in all outcomes at the first and fourth weeks $(\mathrm{p}<0.05)$. When comparing between-group results, only abduction ROM and SPADI scores were significantly relevant for the local injection group ( $\mathrm{p}<0.05)$ (Göksu et al., 2016).

One study assessed KT and its effect in the presence of Achilles tendinopathy (Firth et al., 2010). Firth et al. investigated the effect of short-term KT in comparison with healthy people. Jumping distance and neuron excitability were measured using a single hop test and evoking Hoffman reflex (of the soleus and gastrocnemius muscles), respectively. VISA-A score in the Achilles tendinopathy group revealed a wide range of disability levels among participants, ranging from 21 to 94 . Measurements were taken before the application of the band, during and after its disposal. Results showed no significant differences in the jumping distance when applying the bandage in both groups ( $\mathrm{p}=0.55)$, and, as expected, the affected group did not jump as far as the healthy group $\operatorname{did}(p<0.0005)$. The Hoffman reflex amplitude in the soleus and gastrocnemius increased in the healthy group after removal ( $\mathrm{p}=0.01$ and $\mathrm{p}=0.03$, respectively), while it remained unchanged in people with Achilles tendinopathy ( $\mathrm{p}=0.43$ and $\mathrm{p}=0.16$, respectively) (Firth et al., 2010).

Two studies evaluated KT and its effect in the presence of lateral epicondylitis (Dilek et al., 2016; Liu et al., 2007). Dilek et al. (2016) assessed disability and the stage of the disease by using PRTEQ function subscales and Nirschl score, respectively. KT was applied twice a week for two weeks, and evaluations were done at baseline, at two and six weeks after treatment. Results showed significant changes for all outcomes at two and six weeks $(\mathrm{p}<0.05)$. Liu et al. (2007) studied two volunteers with lateral epicondylitis. Subjects performed both passive and active wrist flexion-extension for periods of two seconds, with and without KT. Motion tracking of the extensor carpi radialis muscles, in terms of longitudinal scans in proximal and distal areas of the lateral epicondyle, were recorded using dynamic ultrasound imaging. These experimental results showed a smaller extension movement after 24 hours of KT than before taping.

Massei et al. (2007) investigated KT effects in the presence of patellar tendinopathy. Knee ROM and dynamic balance were assessed by using a standard goniometer and SEBT score, respectively. Knee ROM measures were taken in the supine position, and SEBT information was obtained based on anterior, anterolateral, anteromedial, posteromedial posterior, posterolateral, medial, and lateral dynamic balance. All subjects received all four taping conditions, divided over four days with at least one day rest in between them. No significant changes in ROM were observed for knee flexion and extension. Regarding dynamic balance, a significant effect was found in anteromedial, lateral and posterolateral directions between taping conditions $(\mathrm{p}<0.05)$. Reach distances were greater for KT in anteromedial and posterolateral directions $(\mathrm{p}<0.05)$; as for lateral directions, significant changes were observed between KT, LT, and PT in comparison with NT $(\mathrm{p}<0.05)$.

\section{Kinesiotape on Pain}

Pain sensation was measured using different evaluation procedures in a total of 10 studies(Au et al., 2017; Chang et al., 2012; Dilek et al., 2016; Firth et al., 2010; Göksu et al., 2016; Homayouni et al., 2013b; Homayouni et al., 2016; Massei et al., 2017; Shakeri et al., 2013; Thelen et al., 2008), nine of them using validated scores such as the Visual Analogic Scale (VAS), Numeric Pain Rating Scale (NPRS), SPADI and PRTEQ (Au et al., 2017; Dilek et al., 2016; Firth et al., 2010; Göksu et al., 2016; Homayouni et al., 2013b; Homayouni et al., 2016; Massei et al., 2017; Shakeri et al., 2013; Thelen et al., 2008). Additionally, algometry was employed in one of the studies (Chang et al., 2012).

Shoulder pain was evaluated in three studies (Göksu et al., 2016; Hassan Shakeri et al., 2013; Thelen et al., 2008). Thelen et al. assessed the short-term effects of KT, using SPADI and VAS scores (Thelen et al., 2008). Subjects were randomly allocated in a therapeutic KT group and a sham KT group, and all measures were taken at baseline, immediately after taping (except SPADI score), three days and six days after tape application. Results showed significant changes within each group, but no between-group differences existed except for VAS on Day 1, which was significantly better for the KT group $(\mathrm{p}=0.01)$. Shakeri et al. evaluated the shortterm effects of KT in comparison with placebo taping (Shakeri et al., 2013). Pain intensity during movement and nocturnal pain were assessed using the VAS scale, and measures were obtained at baseline, immediately after taping, as well as three days and one week after initial application. Significant changes in pain during movement (for KT group) and in nocturnal pain (for both groups) were found; however, they were only significantly greater for the KT group immediately after the initial application; those significant differences did not remain at the end of the study. Goksu et al. (2016) assessed pain in individuals with subacromial impingement syndrome in comparison with local injection therapy, applying KT three times over a three-day interval. Pain at rest and movement was assessed by using 100-mm VAS and SPADI scores, obtaining results at baseline, as well as one week and four weeks after therapy. Significant improvements were found at one and four weeks after treatment in both rest and movement pain variables for both groups $(\mathrm{p}<0.05)$, but only VAS pain at rest and the SPADI score were significant between groups in favour of the local injection therapy group $(\mathrm{p}<0.05)$.

Achilles tendinopathy was assessed in one study. Firth et al. evaluated the effect of KT on pain in comparison with healthy subjects (Firth et al., 2010). A 10-cm VAS score was used to determine the level of pain before tape application, with the tape in place and after tape removal. In addition, pain during a single-hop test was also recorded with and without tape. No significant changes were found in VAS scores by the application of 
this tape nor during the hop test with and without tape ( $\mathrm{p}=0.74)$ (Firth et al., 2010).

Pain in medial elbow tendinopathy was measured only in one study, dealing with baseball pitchers suffering from tendinopathy and comparing them to healthy athletes (Chang et al., 2012). An algometer and a VAS score were used to measure the pressure pain threshold (PPT) and 4-kg pressure pain tolerance, both in the muscle belly and muscle-tendon junction of the common wrist flexors locations. Three taping conditions (no-taping, placebo taping and KT) were applied to each participant with an interval of one week. Results revealed significant changes in PPT and 4-kg pressure pain tolerance in favour of placebo and KT compared to no-taping for both the healthy and affected groups $(\mathrm{p}<0.05)$.

Homayouni et al. measured the effect of KT on pain in those with pes anserinus tendino-bursitis. They compared KT application with nonsteroidal anti-inflammatory drugs and physical therapy (Homayouni et al., 2016). Pain and swelling scores were recorded using VAS and soft tissue sonography. KT was applied three times for three weeks, with a one-week interval, assessing different scores at baseline and after treatment. Results showed significant changes in both groups after interventions for all outcomes ( $\mathrm{p}=0.0001$ ), but KT was significantly more effective for decreasing pain and swelling scores $(\mathrm{p}=0.0001)$.

Lateral epicondylitis was analysed in two studies by Au et al. (2017) and Dilek et al. (2016). The first study addressed pain after applying the following four KT conditions in every patient (inhibitory KT, facilitatory KT, sham KT and untaped) (Au et al., 2017). Similar to grip strength, pain was assessed immediately after each tape application, and an NPRS scale was employed. Pain intensity information was collected during the maximal grip strength test. Results also showed no significant differences in pain intensity among taping conditions ( $\mathrm{p}=0.321$ ). In the second study, KT was applied twice a week over a two-week period, measuring pain at rest, during of daily living activities, night and palpation on lateral epicondyle (Dilek et al., 2016). The VAS and PRTEQ scales were used at baseline, at two and six weeks after treatment. Significant improvements were observed in all parameters at two and six weeks for both VAS and PRTEQ scores $(p<0.001)$.

De Quervain's disease was assessed in one paper in which KT effects on pain in comparison with physical therapy were studied (Homayouni et al., 2013a). Pain and the presence of swelling were measured using a 100-mm VAS score and physician inspection-palpation. KT was applied four times a week, and scores were recorded at baseline and one month after treatment. A significant decrease in VAS was observed at the end of the treatment in both groups $(\mathrm{p}<0.001)$, being more meaningful in the KT group. Swelling changes were significant in the KT group $(\mathrm{p}<0.001)$ but not in the PT group $(\mathrm{p}>0.05)$, showing significantly better results for KT in comparison with PT.

Lastly, the study by Massei et al. (2017) was the only one focusing on patellar tendinopathy. This investigation evaluated pain after the application of four different tape conditions, comprising NT, PT, LT, and KT. These taping modalities were applied to all the participants in four different sessions. An NPRS score was employed to assess pain, recording pre- and post-treatment measures. Results from ANOVA showed no significant effects for time or taping condition.

\section{Discussion}

The theory about the benefits of KT in treating such a wide variety of conditions argues that its properties reduce recovery times due to several effects, such as decreasing pain, improving muscle and joint function, lymphatic circulation and, subsequently, microcirculation and inflammation (Halseth et al., 2004). The purpose of this systematic review was to investigate whether existing evidence supports the implementation of KT dressing technique in patients with tendinopathy. The findings provided conflicting evidence regarding the effectiveness of KT for the treatment of tendinopathies.

This review included 13 studies investigating the effects of kinesiotape for tendinopathies affecting diverse anatomical regions. Of the 13 studies, nine presented upper extremity tendinopathies, and four presented lower extremity tendinopathies. Studies reporting benefits $(n=7)$ were greater in number to those that found no benefit or no significant changes $(n=6)$ (Au et al., 2017; Chang et al., 2012; Chang et al., 2013; Firth et al., 2010; Liu et al., 2007; Massei et al., 2017). However, it is important to note that these improvements were not present at longer-term follow up, did not imply a clinical change in every case, and did not always arise from high-quality research. These results may not be due to methodological quality, however; the studies' methodological scores were generally inadequate, with less than half of the included studies $(n=5)$ (Hsiao-Yun Chang et al., 2012; Göksu et al., 2016; Homayouni et al., 2013a; Shakeri et al., 2013; Thelen et al., 2008) scoring six or more points on the PEDro scale. Blinding of subjects, therapists, and evaluators were not generally achieved, with just two studies accomplishing, at least, two of these items (Au et al., 2017; Thelen et al., 2008) and six studies not fulfilling any of them (Dilek et al., 2016; Griebert et al., 2016; Homayouni et al., 2013b; Liu et al., 2007; Massei et al., 2017; Shakeri et al., 2013). Baseline group characteristics were similar in most of included the studies. Chang et al. (2013) presented no baseline data. The control group of Firth et al. (2010) differed in subjects' age and sex, while three studies just included a single experimental group (Au et al., 2017; Dilek et al., 2016; Griebert et al., 2016).

Regarding direction (origin-insertion theory), time and tensional percentage of the application, there is a lack of agreement in the reviewed literature. Most of the studies followed the "insertion to origin" fashion ac- 
cording to the inhibitory theory so as to stretch the Golgi tendon organ at the distal end of the target muscle, though Griebert et al. (2016) chose to apply from origin to insertion also obtaining consistent results for KT group. Moreover, Au et al. (2017) dealt with both application strategies and showed no significant differences between them, thus refuting the proposed mechanisms suggested by Kase (Halseth et al., 2004), but also noting that two circular holes were cut to allow for EMG electrode placement, which could affect the structure of the tape and subsequently the results. Time of application also differed among studies, varying from immediate application (Au et al., 2017; Firth et al., 2010; Massei et al., 2017), one day (Griebert et al., 2016) and two to three days (Shakeri et al., 2013). Uneven frequencies were also observed, ranging from daily to weekly, by way of two three-day intervals. Although similar designs were found for each type of injury, the stretching percentage of the band was inconsistent between studies, largely relying on the experience of the therapist. There was only one study where stretch tension was standardized, measuring the distance between the line 2 $\mathrm{cm}$ distal to the medial epicondyle of the humerus and the wrist joint line, and then multiplying by 0.8 to set the final length of the band (Chang et al., 2012). However, there was concordance in terms of the follow-up period, mostly lasting less than three weeks, with just three studies evaluating at the fourth week (Göksu et al., 2016; Homayouni et al., 2013a) and sixth week (Dilek et al., 2016).

The previous condition of the patient might have been a determinant for the final results in some studies. For instance, Thelen et al. (2008) allowed prescribed nonsteroidal anti-inflammatory drugs (NSAIDs) intakes prior to research enrolment. Massei et al. (2017) included active individuals (around 150 minutes of moderate to vigorous activity per week), and Goksu et al. (2016) provided guidelines for a home exercise programme, possibly ensuring prolonged pattern corrections which integrate properly with the therapy (Khan et al., 2013).

The KT lifting function over skin is proposed to relieve pressure on nociceptors immediately, thus directly reducing the perceived pain (Halseth et al., 2004). Generally, improvements in pain reduction were found among different studies (Chang et al., 2012; Dilek et al., 2016; Göksu et al., 2016; Homayouni et al., 2013b; Homayouni et al., 2016; Shakeri et al., 2013; Thelen et al., 2008), but its superiority against sham taping or other forms of treatment is not supported. One study found significantly better changes in favour of local injection therapy (Göksu et al., 2016), and six, despite observing significant intra-group changes, showed no significant differences in most of the different variables between sham taping (Au et al., 2017; Chang et al., 2012; Shakeri et al., 2013; Thelen et al., 2008), other taping conditions (Massei et al., 2017) or comparing to healthy subjects(Firth et al., 2010). However, Homayuni et al. (2013a; 2016) observed greater changes for KT in comparison to physical therapy alone and with nonsteroidal anti-inflammatory drugs. Similar results in favour of KT were also found by Dilek et al. (2016), although no comparison group was employed. Interestingly, Thelen (2008) reported no immediate differences between sham taping and KT, indicating that sham application provided a neutral effect as desired.

There is a general agreement on the gate control theory as one plausible explanation for this pain reduction, proposing that tape could stimulate neuromuscular pathways via increased afferent feedback (Kneeshaw, 2002), bringing different impacts to pain receptors and proprioceptors. This increased afferent stimulus to large-diameter nerve fibres, thus mitigating the nociceptive input activity from small-diameter fibres, might have alleviated pain-related symptoms.

Regarding muscle properties, miscellaneous findings can be observed in the literature. Strength improvements due to KT were not superior against other forms of taping (Au et al., 2017; Chang et al., 2012; Chang et al., 2013) or healthy subjects (Chang et al., 2013). Au et al. (2017) conducted all the tests in a single session, with just five minutes of rest between each taping condition, which could have led to muscle fatigue and alteration of the results. Massei et al. (2017) found no significant changes in power between taping conditions revealing, however, an increasing effect in knee flexor strength. It has been reported that the presence of swelling or oedema within the knee joint may inhibit muscular strength (Spencer et al., 1984). A possible anti-inflammatory KT effect, in addition to observed clinical changes in pain, could have influenced these results. Griebert et al. (2016) found significant immediate improvements in medial midfoot and lateral forefoot load forces in patients with MTSS following the immediate application of KT in the first hours. It seems noteworthy that loading capacity was better in the healthy group at baseline, supporting the presence of biomechanical differences among patients and the possible corrective effect following the application of the tape. However, a single experimental-group design was carried out in three of the mentioned studies (Au et al., 2017; Dilek et al., 2016; Massei et al., 2017), which could complicate the process of contextualizing and interpreting the results.

In terms of functionality, KT effects are not generally greater than other forms of treatment. Despite showing significant changes in different variables, most of them were not superior to sham tape (Shakeri et al., 2013; Thelen et al., 2008), other taping conditions (Massei et al., 2017), or local injection therapy (Göksu et al., 2016), showing this invasive modality better results in terms of shoulder abduction and SPADI scores. Firth et al. (2010) found significant increases in the Hoffman reflex excitability only in healthy subjects, and three studies (Au et al., 2017; Dilek et al., 2016; Griebert et al., 2016) did not include a control group, making the gathering of comparative information impossible to accomplish. However, Thelen et al. (2008) and Shakeri et al. (2013) reported immediate meaningful differences in shoulder abduction ROM in KT group, clinically consistent with previous reports circumscribing these positive effects to musculoskeletal shoulder pain at the short-term, although in combination with a home exercise programme (Kaya et al., 2011). One study (Liu et 
al., 2007) proposed a new dynamic ultrasound motion tracking algorithm for the extensor carpi radialis muscles in subjects with lateral epicondylitis, showing that movement after 24 hours of KT is smaller than before taping, which could apparently correlate with the assumed constriction effect of the tape.

Synthesis of the evidence proved difficult for several reasons. The methodological quality of the studies selected was poor. The main limitation of the present review is the low quality of the included studies, limiting clinical decisions based on strong evidence. Poor blinding procedures, lack of randomization, and lack of intention to treat analysis may have weakened the scientific merit of the reviewed papers due to increased potential biases. Additionally, the studies presented small sample sizes and very heterogeneous characteristics regarding age and clinical status, which may interfere with the validity of data. Clinical application of KT was either poorly reported or varied between studies, even when managing the same condition.

\section{Conclusion}

This systematic review identified thirteen studies reporting on the effectiveness of KT for treatment of tendinopathies and found that there is limited evidence to support KT for the treatment of these pathologies, especially for anything beyond the short-term. Only a small proportion of the included studies were randomized controlled trials showing real benefits, with other employing observational designs using relatively small sample sizes and no control group. In addition, improvements related to KT were not generally greater in comparison with other treatment modalities. Further research with rigorous methodological approaches, assuming more homogeneous and larger samples, thus reinforcing external validity and the generalization of the results, is needed to support the use of KT for tendinopathies.

\section{References}

Abubaker, A. A., \& Muaidi, Q. I. (2018). The Effect of the Inhibition Technique of the Kinesio Taping on the Triceps Surae Muscle after an Isokinetic Fatigue Protocol. MOJ Orthopedics \& Rheumatology, 10(1), 00384.

Aguilar-Ferrándiz, M. E., Castro-Sánchez, A. M., Matarán-Peñarrocha, G. A., Guisado-Barrilao, R., GarcíaRíos, M. C., \& Moreno-Lorenzo, C. (2014). A randomised controlled trial of a mixed Kinesio tapingcompression technique on venous symptoms, pain, peripheral venous flow, clinical severity and overall health status in postmenopausal women with chronic venous insufficiency. Clinical Rehabilitation, 28(1), 69-81. doi: 10.1177/0269215512469120

Aicale, R., Tarantino, D., \& Maffulli, N. (2018). Overuse injuries in sport: A comprehensive overview. Journal of Orthopaedic Surgery and Research, 13. doi: 10.1186/s13018-018-1017-5

Aktürk, S., Büyükavc1, R., Aslan, Ö., \& Ersoy, Y. (2018). Comparison of splinting and Kinesio taping in the treatment of carpal tunnel syndrome: A prospective randomised study. Clinical Rheumatology, 37(9), 2465-2469. doi: 10.1007/s10067-018-4176-1

Andia, I., Latorre, P. M., Gomez, M. C., Burgos-Alonso, N., Abate, M., \& Maffulli, N. (2014). Platelet-rich plasma in the conservative treatment of painful tendinopathy: A systematic review and meta-analysis of controlled studies. British Medical Bulletin, 110(1), 99-115. doi: 10.1093/bmb/ldu007

Au, I. P. H., Fan, P. C. P., Lee, W. Y., Leong, M. W., Tang, O. Y., An, W. W., \& Cheung, R. T. (2017). Effects of Kinesio tape in individuals with lateral epicondylitis: A deceptive crossover trial. Physiotherapy Theory and Practice, 33(12), 914-919. doi: 10.1080/09593985.2017.1359871

Ay, S., Konak, H. E., Evcik, D., \& Kibar, S. (2017). The effectiveness of Kinesio Taping on pain and disability in cervical myofascial pain syndrome. Revista Brasileira De Reumatologia, 57(2), 93-99. doi: 10.1016/j. rbre.2016.03.012

Berezutsky, V. (2018). Possibilities of kinesio taping to prevent injuries of professional dancers. International Journal of Occupational Safety and Ergonomics: JOSE, 1-8. doi: 10.1080/10803548.2018.1433281

Bischoff, L., Babisch, C., Babisch, J., Layher, F., Sander, K., Matziolis, G., Pietsch, S., \& Röhner, E. (2018). Effects on proprioception by Kinesio taping of the knee after anterior cruciate ligament rupture. European Journal of Orthopaedic Surgery \& Traumatology: Orthopedie Traumatologie, 28(6), 1157-1164. doi: 10.1007/s00590-018-2167-1

Campbell, S. A., \& Valier, A. R. (2016). The Effect of Kinesio Taping on Anterior Knee Pain Consistent With Patellofemoral Pain Syndrome: A Critically Appraised Topic. Journal of Sport Rehabilitation, 25(3), 288293. doi: 10-1123/jsr.2014-0278

Chang, Hsiao-Yun, Huang, Y.-H., Cheng, S.-C., Yeh, C.-Y., \& Wang, C.-H. (2018). Prophylactic Kinesio taping enhances balance for healthy collegiate players. The Journal of Sports Medicine and Physical Fitness, 58(5), 651-658. doi: 10.23736/S0022-4707.17.06955-9

Chang, Hsiao-Yun, Wang, C.-H., Chou, K.-Y., \& Cheng, S.-C. (2012). Could forearm Kinesio Taping improve strength, force sense, and pain in baseball pitchers with medial epicondylitis? Clinical Journal of Sport Medicine: Official Journal of the Canadian Academy of Sport Medicine, 22(4), 327-333. doi: 10.1097/ JSM.0b013e318254d7cd

Chang, H.-Y., Cheng, S.-C., Lin, C.-C., Chou, K.-Y., Gan, S.-M., \& Wang, C.-H. (2013). The effectiveness of kinesio taping for athletes with medial elbow epicondylar tendinopathy. International Journal of Sports Medicine, 34(11), 1003-1006. doi: 10.1055/s-0033-1333747

Chang, W.-D., Chen, F.-C., Lee, C.-L., Lin, H.-Y., \& Lai, P.-T. (2015). Effects of Kinesio Taping versus McConnell Taping for Patellofemoral Pain Syndrome: A Systematic Review and Meta-Analysis. Evidence- 
Based Complementary and Alternative Medicine: ECAM, 2015, 471208. doi: 10.1155/2015/471208

Costin, B. R. (2018). Kinesio Tape for Treatment of Lower Eyelid Festoons. Ophthalmic Plastic and Reconstructive Surgery, 34(6), 602. doi: 10.1097/IOP.0000000000001242

Davison, E. A., Anderson, C. T., Ponist, B. H., Werner, D. M., Jacobs, M. E., Thompson, A. J., \& Cook, M. R. (2016). Inhibitory Effect of the Kinesio Taping Method on the Gastrocnemius Muscle. American Journal of Sports Science and Medicine, 4(2), 33-38. doi: 10.12691/ajssm-4-2-2

de Vos, R. J., van Veldhoven, P. L. J., Moen, M. H., Weir, A., Tol, J. L., \& Maffulli, N. (2010). Autologous growth factor injections in chronic tendinopathy: A systematic review. British Medical Bulletin, 95, 63-77. doi: 10.1093/bmb/ldq006

Dilek, B., Batmaz, I., Sarıyıldız, M. A., Sahin, E., Ilter, L., Gulbahar, S., Cevik, R., \& Nas, K. (2016). Kinesio taping in patients with lateral epicondylitis. Journal of Back and Musculoskeletal Rehabilitation, 29(4), 853-858. doi: 10.3233/BMR-160701

Docheva, D., Müller, S. A., Majewski, M., \& Evans, C. H. (2015). Biologics for tendon repair. Advanced Drug Delivery Reviews, 84, 222-239. doi: 10.1016/j.addr.2014.11.015

Firth, B. L., Dingley, P., Davies, E. R., Lewis, J. S., \& Alexander, C. M. (2010). The effect of kinesiotape on function, pain, and motoneuronal excitability in healthy people and people with Achilles tendinopathy. Clinical Journal of Sport Medicine: Official Journal of the Canadian Academy of Sport Medicine, 20(6), 416421. doi: 10.1097/JSM.0b013e3181f479b0

Foley, N. C., Teasell, R. W., Bhogal, S. K., \& Speechley, M. R. (2003). Stroke Rehabilitation Evidence-Based Review: Methodology. Topics in Stroke Rehabilitation, 10(1), 1-7.

Fournier, P. E., \& Rappoport, G. (2005). [Tendinopathy: Physiopathology and conservative treatment]. Revue Medicale Suisse, 1(28), 1840-1842, 1845-1846.

Gambito, E. D., Gonzalez-Suarez, C. B., Oquiñena, T. I., \& Agbayani, R. B. (2010). Evidence on the effectiveness of topical nitroglycerin in the treatment of tendinopathies: A systematic review and meta-analysis. Archives of Physical Medicine and Rehabilitation, 91(8), 1291-1305. doi: 10.1016/j.apmr.2010.02.008

Göksu, H., Tuncay, F., \& Borman, P. (2016). The comparative efficacy of kinesio taping and local injection therapy in patients with subacromial impingement syndrome. Acta Orthopaedica Et Traumatologica Turcica, 50(5), 483-488. doi: 10.1016/j.aott.2016.08.015

Griebert, M. C., Needle, A. R., McConnell, J., \& Kaminski, T. W. (2016). Lower-leg Kinesio tape reduces rate of loading in participants with medial tibial stress syndrome. Physical Therapy in Sport: Official Journal of the Association of Chartered Physiotherapists in Sports Medicine, 18, 62-67. doi: 10.1016/j.ptsp.2014.01.001

Habets, B., \& van Cingel, R. E. H. (2015). Eccentric exercise training in chronic mid-portion Achilles tendinopathy: A systematic review on different protocols. Scandinavian Journal of Medicine \& Science in Sports, 25(1), 3-15. doi: 10.1111/sms.12208

Halseth, T., McChesney, J. W., Debeliso, M., Vaughn, R., \& Lien, J. (2004). The effects of kinesio ${ }^{\mathrm{TM}}$ taping on proprioception at the ankle. Journal of Sports Science \& Medicine, 3(1), 1-7.

Hazar Kanik, Z., Citaker, S., Demirtas, C. Y., Bukan, N. C., Celik, B., \& Gunaydin, G. (2018). Effects of KinesioTaping on the Relief of Delayed Onset Muscle Soreness: A Randomised, Placebo-Controlled Trial. Journal of Sport Rehabilitation, 1-22. doi: 10.1123/jsr.2018-0040

Homayouni, K., Zeynali, L., \& Mianehsaz, E. (2013a). Comparison between kinesio taping and physiotherapy in the treatment of De Quervain's Disease. J Musculoskelet Res, 16(4), 169.

Homayouni, K., Zeynali, L., \& Mianehsaz, E. (2013b). Comparison between Kinesio taping and physiotherapy in the treatment of De Quervain's disease. Journal of Musculoskeletal Research, 16(4), 1350019.

Homayouni, Kaynoosh, Foruzi, S., \& Kalhori, F. (2016). Effects of kinesiotaping versus nonsteroidal anti-inflammatory drugs and physical therapy for treatment of pes anserinus tendino-bursitis: A randomised comparative clinical trial. The Physician and Sportsmedicine, 44(3), 252-256. doi: 10.1080/00913847.2016.1199251

Hosp, S., Bottoni, G., Heinrich, D., Kofler, P., Hasler, M., \& Nachbauer, W. (2015). A pilot study of the effect of Kinesiology tape on knee proprioception after physical activity in healthy women. Journal of Science and Medicine in Sport, 18(6), 709-713. doi: 10.1016/j.jsams.2014.09.004

Hsu, Y.-H., Chen, W.-Y., Lin, H.-C., Wang, W. T. J., \& Shih, Y.-F. (2009). The effects of taping on scapular kinematics and muscle performance in baseball players with shoulder impingement syndrome. Journal of Electromyography and Kinesiology: Official Journal of the International Society of Electrophysiological Kinesiology, 19(6), 1092-1099. doi: 10.1016/j.jelekin.2008.11.003

Jaraczewska, E., \& Long, C. (2006). Kinesio taping in stroke: Improving functional use of the upper extremity in hemiplegia. Topics in Stroke Rehabilitation, 13(3), 31-42. doi: 10.1310/33KA-XYE3-QWJB-WGT6

Kalichman, L., Vered, E., \& Volchek, L. (2010). Relieving symptoms of meralgia paresthetica using Kinesio taping: A pilot study. Archives of Physical Medicine and Rehabilitation, 91(7), 1137-1139. doi: 10.1016/j. apmr.2010.03.013

Kaux, J.-F., Forthomme, B., Goff, C. L., Crielaard, J.-M., \& Croisier, J.-L. (2011). Current opinions on tendinopathy. Journal of Sports Science \& Medicine, 10(2), 238-253.

Kaya, E., Zinnuroglu, M., \& Tugcu, I. (2011). Kinesio taping compared to physical therapy modalities for the treatment of shoulder impingement syndrome. Clinical Rheumatology, 30(2), 201-207. doi: 10.1007/ s10067-010-1475-6

Kearney, R., \& Costa, M. L. (2010). Insertional achilles tendinopathy management: A systematic review. Foot 
\& Ankle International / American Orthopaedic Foot and Ankle Society [and] Swiss Foot and Ankle Society, 31(8), 689-694. doi: 10.3113/FAI.2010.0689

Khan, K. M., \& Scott, A. (2009). Mechanotherapy: How physical therapists' prescription of exercise promotes tissue repair. British Journal of Sports Medicine, 43(4), 247-252. doi: 10.1136/bjsm.2008.054239

Khan, Y., Nagy, M. T., Malal, J., \& Waseem, M. (2013). The painful shoulder: Shoulder impingement syndrome. The Open Orthopaedics Journal, 7, 347-351. doi: 10.2174/1874325001307010347

Kneeshaw, D. (2002). Shoulder taping in the clinical setting. J Bodywork Move Ther, 6(1), 2-8.

Krajczy, M., Luniewski, J., Bogacz, K., \& Szczegielniak, J. (2018). Evaluation of applying Kinesio taping in children with urinary incontinence. Journal of Pediatric Urology. doi: 10.1016/j.jpurol.2018.06.013

Kurt, E. E., Büyükturan, Ö., Erdem, H. R., Tuncay, F., \& Sezgin, H. (2016). Short-term effects of kinesio tape on joint position sense, isokinetic measurements, and clinical parameters in patellofemoral pain syndrome. Journal of Physical Therapy Science, 28(7), 2034-2040. doi: 10.1589/jpts.28.2034

Larsson, M. E. H., Käll, I., \& Nilsson-Helander, K. (2012). Treatment of patellar tendinopathy-A systematic review of randomised controlled trials. Knee Surgery, Sports Traumatology, Arthroscopy: Official Journal of the ESSKA, 20(8), 1632-1646. doi: 10.1007/s00167-011-1825-1

Lee, J., \& Yoo, W. (2012). Treatment of chronic Achilles tendon pain by Kinesio taping in an amateur badminton player. Physical Therapy in Sport: Official Journal of the Association of Chartered Physiotherapists in Sports Medicine, 13(2), 115-119. doi: 10.1016/j.ptsp.2011.07.002

Li, Y., Yin, Y., Jia, G., Chen, H., Yu, L., \& Wu, D. (2018). Effects of kinesiotape on pain and disability in individuals with chronic low back pain: A systematic review and meta-analysis of randomised controlled trials. Clinical Rehabilitation, 269215518817804. doi: 10.1177/0269215518817804

Liberati, A., Altman, D. G., Tetzlaff, J., Mulrow, C., Gøtzsche, P. C., Ioannidis, J. P. A., Clarke, M., Devereaux, P. J., Kleijnen, J., \& Moher, D. (2009). The PRISMA statement for reporting systematic reviews and metaanalyses of studies that evaluate health care interventions: Explanation and elaboration. Journal of Clinical Epidemiology, 62(10), e1-34. doi: 10.1016/j.jclinepi.2009.06.006

Lim, C., Park, Y., \& Bae, Y. (2013). The effect of the kinesio taping and spiral taping on menstrual pain and premenstrual syndrome. Journal of Physical Therapy Science, 25(7), 761-764. doi: 10.1589/jpts.25.761

Littlewood, C., Ashton, J., Chance-Larsen, K., May, S., \& Sturrock, B. (2012). Exercise for rotator cuff tendinopathy: A systematic review. Physiotherapy, 98(2), 101-109. doi: 10.1016/j.physio.2011.08.002

Liu, Y.-H., Chen, S.-M., Lin, C.-Y., Huang, C.-I., \& Sun, Y.-N. (2007). Motion tracking on elbow tissue from ultrasonic image sequence for patients with lateral epicondylitis. Conference Proceedings: ... Annual International Conference of the IEEE Engineering in Medicine and Biology Society. IEEE Engineering in Medicine and Biology Society. Annual Conference, 2007, 95-98. doi: 10.1109/IEMBS.2007.4352231

Lui, P. P. Y., \& Ng, S. W. (2013). Cell therapy for the treatment of tendinopathy-A systematic review on the pre-clinical and clinical evidence. Seminars in Arthritis and Rheumatism, 42(6), 651-666. doi: 10.1016/j. semarthrit.2012.10.004

Maher, C. G., Sherrington, C., Herbert, R. D., Moseley, A. M., \& Elkins, M. (2003). Reliability of the PEDro scale for rating quality of randomised controlled trials. Physical Therapy, 83(8), 713-721.

Massei, M., Sanzo, P., \& Przysucha, E. (2017). The Use of Therapeutic Taping in Individuals with Patellar Tendinopathy. International Journal of Prevention and Treatment, 6(1), 4-11.

Moseley, A. M., Herbert, R. D., Sherrington, C., \& Maher, C. G. (2002). Evidence for physiotherapy practice: A survey of the Physiotherapy Evidence Database (PEDro). The Australian Journal of Physiotherapy, 48(1), 43-49.

Mostafavifar, M., Wertz, J., \& Borchers, J. (2012). A systematic review of the effectiveness of kinesio taping for musculoskeletal injury. The Physician and Sportsmedicine, 40(4), 33-40. doi: 10.3810/psm.2012.11.1986

Nelson, N. L. (2016). Kinesio taping for chronic low back pain: A systematic review. Journal of Bodywork and Movement Therapies, 20(3), 672-681. doi: 10.1016/j.jbmt.2016.04.018

Parreira, P. do C. S., Costa, L. da C. M., Hespanhol, L. C., Lopes, A. D., \& Costa, L. O. P. (2014). Current evidence does not support the use of Kinesio Taping in clinical practice: A systematic review. Journal of Physiotherapy, 60(1), 31-39. doi: 10.1016/j.jphys.2013.12.008

Rees, J. D., Wilson, A. M., \& Wolman, R. L. (2006). Current concepts in the management of tendon disorders. Rheumatology, 45(5), 508-521. doi: 10.1093/rheumatology/kel046

Rees, Jonathan D, Stride, M., \& Scott, A. (2014). Tendons - time to revisit inflammation. British Journal of Sports Medicine, 48(21), 1553-1557. doi: 10.1136/bjsports-2012-091957

Sanderson, L. M., \& Bryant, A. (2015). Effectiveness and safety of prolotherapy injections for management of lower limb tendinopathy and fasciopathy: A systematic review. Journal of Foot and Ankle Research, 8, 57. doi: 10.1186/s13047-015-0114-5

Seo, H.-D., Kim, M.-Y., Choi, J.-E., Lim, G.-H., Jung, S.-I., Park, S.-H., Cheon, S.-H., \& Lee, H.-Y. (2016). Effects of Kinesio taping on joint position sense of the ankle. Journal of Physical Therapy Science, 28(4), 1158-1160. doi: $10.1589 /$ jpts.28.1158

Shakeri, H., Keshavarz, R., Arab, A. M., \& Ebrahimi, I. (2013). Therapeutic Effect of Kinesio-taping on Disability of Arm, Shoulder, and Hand in Patients with Subacromial Impingement Syndrome: A Randomised Clinical Trial. Journal of Novel Physiotherapies, 3(4), 169.

Shakeri, Hassan, Keshavarz, R., Arab, A. M., \& Ebrahimi, I. (2013). Clinical effectiveness of kinesiological taping on pain and pain-free shoulder range of motion in patients with shoulder impingement syndrome: 
a randomised, double blinded, placebo-controlled trial. International Journal of Sports Physical Therapy, $8(6), 800-810$

Shih, Y.-F., Lee, Y.-F., \& Chen, W.-Y. (2018). Effects of Kinesiology Taping on Scapular Reposition Accuracy, Kinematics, and Muscle Activity in Athletes With Shoulder Impingement Syndrome: A Randomized Controlled Study. Journal of Sport Rehabilitation, 27(6), 560-569. doi: 10.1123/jsr.2017-0043

Skjong, C. C., Meininger, A. K., \& Ho, S. S. W. (2012). Tendinopathy treatment: Where is the evidence? Clinics in Sports Medicine, 31(2), 329-350. doi: 10.1016/j.csm.2011.11.003

Spencer, J. D., Hayes, K. C., \& Alexander, I. J. (1984). Knee joint effusion and quadriceps reflex inhibition in man. Archives of Physical Medicine and Rehabilitation, 65(4), 171-177.

Taradaj, J., Halski, T., Zduńczyk, M., Rajfur, J., Pasternok, M., Chmielewska, D., Piecha, M., Kwaśna, K., \& Skrzypulec-Plinta, V. (2014). Evaluation of the effectiveness of kinesio taping application in a patient with secondary lymphedema in breast cancer: A case report. Przeglad Menopauzalny = Menopause Review, 13(1), 73-77. doi: 10.5114/pm.2014.41082

Thelen, M. D., Dauber, J. A., \& Stoneman, P. D. (2008). The clinical efficacy of kinesio tape for shoulder pain: A randomised, double-blinded, clinical trial. The Journal of Orthopaedic and Sports Physical Therapy, 38(7), 389-395. doi: 10.2519/jospt.2008.2791

Tsai, H.-J., Hung, H.-C., Yang, J.-L., Huang, C.-S., \& Tsauo, J.-Y. (2009). Could Kinesio tape replace the bandage in decongestive lymphatic therapy for breast-cancer-related lymphedema? A pilot study. Supportive Care in Cancer: Official Journal of the Multinational Association of Supportive Care in Cancer, 17(11), 13531360. doi: 10.1007/s00520-009-0592-8

Unger, M., Carstens, J. P., Fernandes, N., Pretorius, R., Pronk, S., Robinson, A. C., \& Scheepers, K. (2018). The efficacy of kinesiology taping for improving gross motor function in children with cerebral palsy: A systematic review. The South African Journal of Physiotherapy, 74(1), 459. doi: 10.4102/sajp.v74i1.459

Vercelli, S., Ferriero, G., Bravini, E., \& Sartorio, F. (2013). How much is Kinesio taping a psychological crutch? Manual Therapy, 18(3), e11. doi: 10.1016/j.math.2012.10.008

Wang, Y., Gu, Y., Chen, J., Luo, W., He, W., Han, Z., \& Tian, J. (2018). Kinesio taping is superior to other taping methods in ankle functional performance improvement: A systematic review and meta-analysis. Clinical Rehabilitation, 32(11), 1472-1481. doi: 10.1177/0269215518780443

Williams, S., Whatman, C., Hume, P. A., \& Sheerin, K. (2012). Kinesio taping in treatment and prevention of sports injuries: A meta-analysis of the evidence for its effectiveness. Sports Medicine, 42(2), 153-164. doi: $10.2165 / 11594960-000000000-00000$

Wilson, B., \& Bialocerkowski, A. (2015). The Effects of Kinesiotape Applied to the Lateral Aspect of the Ankle: Relevance to Ankle Sprains--A Systematic Review. PloS One, 10(6), e0124214. doi: 10.1371/journal. pone. 0124214

Wilson, F., Walshe, M., O’Dwyer, T., Bennett, K., Mockler, D., \& Bleakley, C. (2018). Exercise, orthoses and splinting for treating Achilles tendinopathy: A systematic review with meta-analysis. British Journal of Sports Medicine, 52(24), 1564-1574. doi: 10.1136/bjsports-2017-098913

Wong, O. M. H., Cheung, R. T. H., \& Li, R. C. T. (2012). Isokinetic knee function in healthy subjects with and without Kinesio taping. Physical Therapy in Sport: Official Journal of the Association of Chartered Physiotherapists in Sports Medicine, 13(4), 255-258. doi: 10.1016/j.ptsp.2012.01.004

Yeung, S. S., Yeung, E. W., Sakunkaruna, Y., Mingsoongnern, S., Hung, W. Y., Fan, Y. L., \& Iao, H. C. (2015). Acute effects of kinesio taping on knee extensor peak torque and electromyographic activity after exhaustive isometric knee extension in healthy young adults. Clinical Journal of Sport Medicine: Official Journal of the Canadian Academy of Sport Medicine, 25(3), 284-290. doi: 10.1097/JSM.0000000000000132

Yoshida, A., \& Kahanov, L. (2007). The effect of kinesio taping on lower trunk range of motions. Research in Sports Medicine, 15(2), 103-112. doi: 10.1080/15438620701405206 